\title{
Tip-Timing Measurements and Numerical Analysis of Last-Stage Steam Turbine Mistuned Bladed Disc During Run-Down
}

\author{
Romuald Rzadkowski ${ }^{1,2}$ (1) $\cdot$ Leszek Kubitz $^{1} \cdot$ Michał Maziarz $^{1} \cdot$ Pawel Troka $^{1} \cdot$ Krzysztof Dominiczak $^{1}$ • \\ Ryszard Szczepanik ${ }^{2}$
}

Received: 23 December 2018 / Revised: 3 October 2019 / Accepted: 12 October 2019 / Published online: 25 October 2019

(c) The Author(s) 2019

\begin{abstract}
Background This paper presents the experimental and numerical studies of last-stage low-pressure (LP) mistuned steam turbine bladed discs during run-down.

Methods The natural frequencies and mode shapes of the turbine bladed disc were calculated using an FE model. The influence of the shaft on the modal properties, such as natural frequencies and mode shapes, was considered. The tip-timing method was used to find the mistuned bladed disc modes and frequencies.

Conclusions The experimental results from the tip-timing analysis show that the mistuning in combination with shaft coupling suppresses pure nodal diameter type blade vibrations associated with the fundamental mode shape of a cantilevered blade. Vibration modes emerge when even a single blade is vibrating due to the well-known mode localization caused by mistuning. The numerical results confirm this.
\end{abstract}

Keywords Steam turbine $\cdot$ Mistuned bladed disc $\cdot$ Rotor $\cdot$ Multistage coupling $\cdot$ Tip-timing

\section{Introduction}

In the most commonly used low-pressure steam turbines, during certain summer exploitation conditions, a problem concerning high-level vibrations in unshrouded last-stage low-pressure blades was reported. In Rzadkowski et al. [1], different models of bladed discs were assumed. The first one was simply a bladed disc without a shaft and the second was a bladed disc with part of the shaft. It was found that the low-pressure (LP) steam turbine last-stage bladed disc is very sensitive to any kind of mistuning. Even the smallest changes in the natural frequencies of blades distort nodal diameters. A numerical study of a steam turbine bladed disc with real, small mistuning showed that nodal diameters do not appear in the first mode family associated with the fundamental mode shape of a cantilevered blade and only individual blades vibrate. Numerical analyses require

Romuald Rzadkowski

z3@imp.gda.pl

1 Institute of Fluid-Flow Machinery Polish Academy of Sciences, Fiszera 14, 80-952 Gdansk, Poland

2 Air Force Institute of Technology, Księcia Bolesława, 6, 01-494 Warsaw, Poland experimental verification. Przysowa et al. [2,3] presented a tip-timing system and its measurements of last-stage rotor blades in a vacuum spin chamber during run-down. A review of tip-timing models is presented in Rzadkowski et al. [4]. The crack propagation using tip-timing of rotor blades is presented in Rzadkowski at el. [5]. Experimental and numerical results of the last-stage low-pressure rotor blade flutter were presented by Sanvito et al. [6]. The 120 blades were grouped in packs of eight blades welded together with lashing wires. Other studies have shown that high-vibration blade amplitudes generally occur in LP steam turbines when there is low output power and high condenser pressure [7-10].

The numerical results for a single mistuned bladed disc show that in a LP last stage, small mistuning can cause only one blade or a very limited number of blades to vibrate, even in first bladed disc vibration series associated with the first cantilever blade mode. This work confirms the numerical finding experimentally using tip-timing measurements during run-down.

A comparison of numerical calculations and experimental measurements for a single mistuned bladed disc was not satisfactory. Therefore, in this paper, a shaft with mistuned bladed discs will be considered to analyse numerically and experimentally measured multistage coupling and the 
influence of the shaft on bladed disc modes during run-down in a vacuum spin chamber. The numerical results will be compared with the tip-timing measurements of mistuned bladed disc frequencies and modes.

Bladh et al. [11], Shahab and Thomas [12], Sharma et al. [13], Sinha [14] and Laxalde et al. [15] analysed the effects of multistage coupling on mistuned bladed disc dynamics. The above studies analysed only a few mistuned bladed discs, which is insufficient for multistage coupling investigation.

A proper analysis of multistage coupling requires investigating tuned bladed discs on a shaft. The forced vibration of eight tuned bladed discs with different numbers of blades on a shaft was analysed by Rzadkowski and Drewczynski [16]. The analysis showed that a tuned bladed disc on a shaft can produce multistage coupling.

Next eight mistuned bladed discs on a shaft were analysed by Rzadkowski and Maurin in $[17,18]$. The nodal diameters of mode shapes were primarily distorted in mistuned unshrouded bladed discs. Moreover, multistage coupling occurred between various nodal diameters. Particular bladed discs in the mistuned system vibrated with modes of various nodal diameters. For instance, one bladed disc vibrated with two nodal diameters and other discs vibrated with one or zero nodal diameters.

Free and forced vibrations of real geometry aircraft engine mistuned bladed discs in a rotor were next analysed by Rzadkowski et al. [19]. Here, the effects of multistage coupling were considerable.

Simulated combustion chamber excitations were used by Rzadkowski and Maurin to study the effect of multistage coupling on the compressor stages and turbine stage in [20].

\section{Experimental Results}

A LP last stage mistuned bladed disc on a rotor was tested in a vacuum spin chamber to measure blade vibration. Fourteen blade vibration measurement sensors (developed by the Air Force Institute of Technology, Przysowa et al. [2, 3]) were installed in seven positions (two sensors at different axial position by one location) (Fig. 1). An additional sensor, mounted between the rotor's front support and stage, generated a signal every revolution. In vacuum chamber experiments, the excitations were caused by air flow from a single pipe.

Blade tip deflections were captured by single-coil inductive sensors. Each sensor had a ceramic core containing a neodymium magnet and coil. A telescopic air excitation pipe with an appropriately shaped nozzle was connected to a reinforced rubber hose. The air flow was regulated manually. The 14 sensors, two at each circumferential location, are shown in Fig. 1.

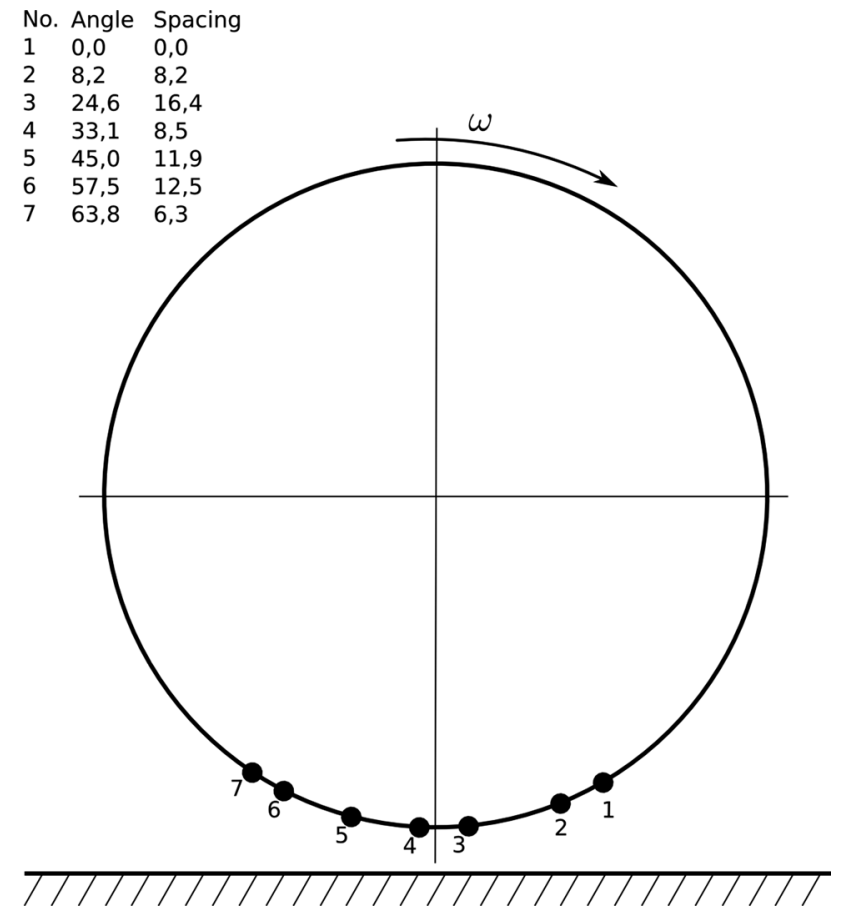

Fig. 1 Tip-timing probe arrangement

The blade displacements were measured during rundown. Figures 2 and 3 present the 53 blade tip displacements during a run-down from 2016 to $1516 \mathrm{rpm}$. We are going to consider only the first group of frequencies associated with the fundamental mode shape of a cantilevered blade. To prevent excessive blade stress through self-excitation, the geometries of the blades were deliberately mistuned by removing a thin layer of material from around the tip of every second blade (feathering, see Fig. 4).

Mistuning was measured by tip-timing analysis. Two types of mistuning were considered. The first was an $11 \%$ mistuning as a result of feathering (Fig. 4). The feathering involved changing the geometry of every second blade to create two groups of blades. In both groups, the mistuning was around $0.5 \%$. Figure 2 shows the blade feathering caused a number of frequency groups for EO3 excitations connected with the blade's natural frequency.

On axis $x$, the number of blades is from 1 to 53. Axis $y$ presents the rotation frequency. The reason why in Fig. 2 blade 2 has a lower resonance frequency at $1720 \mathrm{rpm}$ than blade 1 at $1916 \mathrm{rpm}$ is because of feathering (Fig. 4). Blade 10 has a resonance frequency at $1924 \mathrm{rpm}$ due to the feathering pattern (Fig. 4). Figures 2 and 3 show the vibration amplitudes of all the blades. For example, the $4 \mathrm{~mm}$ distance from the blade 2 line base to its resonance peak corresponds to a blade amplitude of $6 \mathrm{~mm}$.

Figure 3 (an enlarged section of Fig. 2) presents 27 blade tip displacements during a run-down from 1958 to $1878 \mathrm{rpm}$ 
Fig. 2 Tip displacements of 53 rotor blades during run-down, 2016-1516 rpm

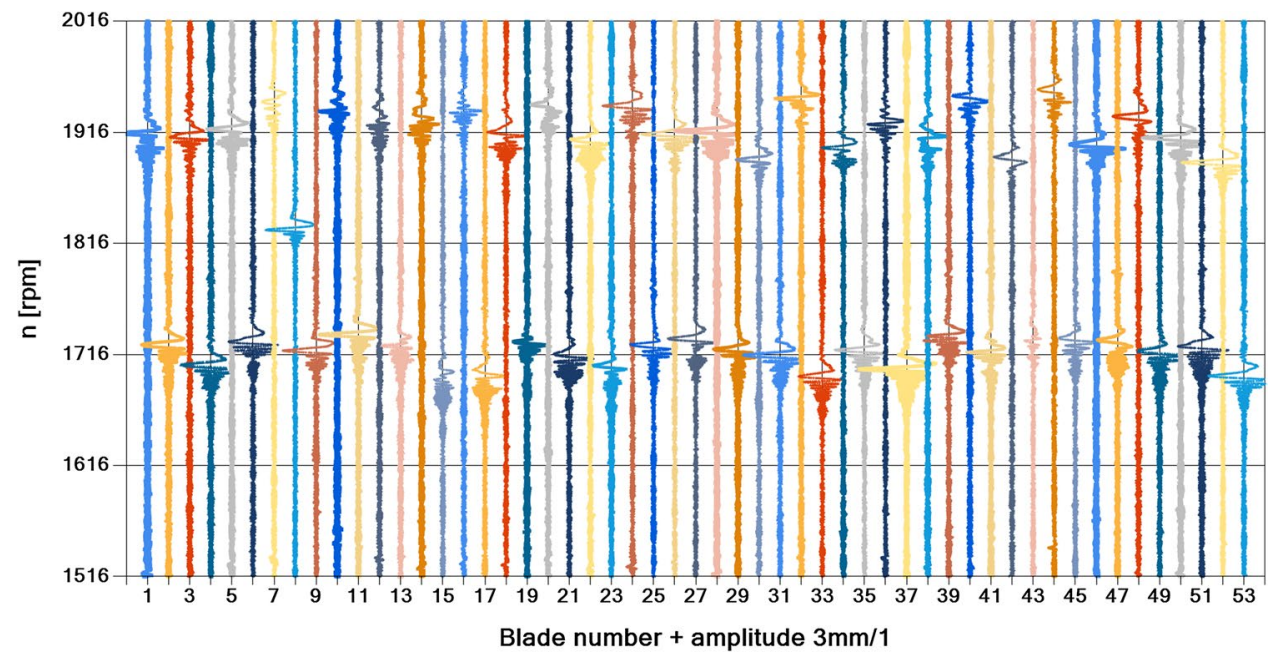

Fig. 3 Tip displacements of 53 rotor blades during run-down, 1958-1878 rpm

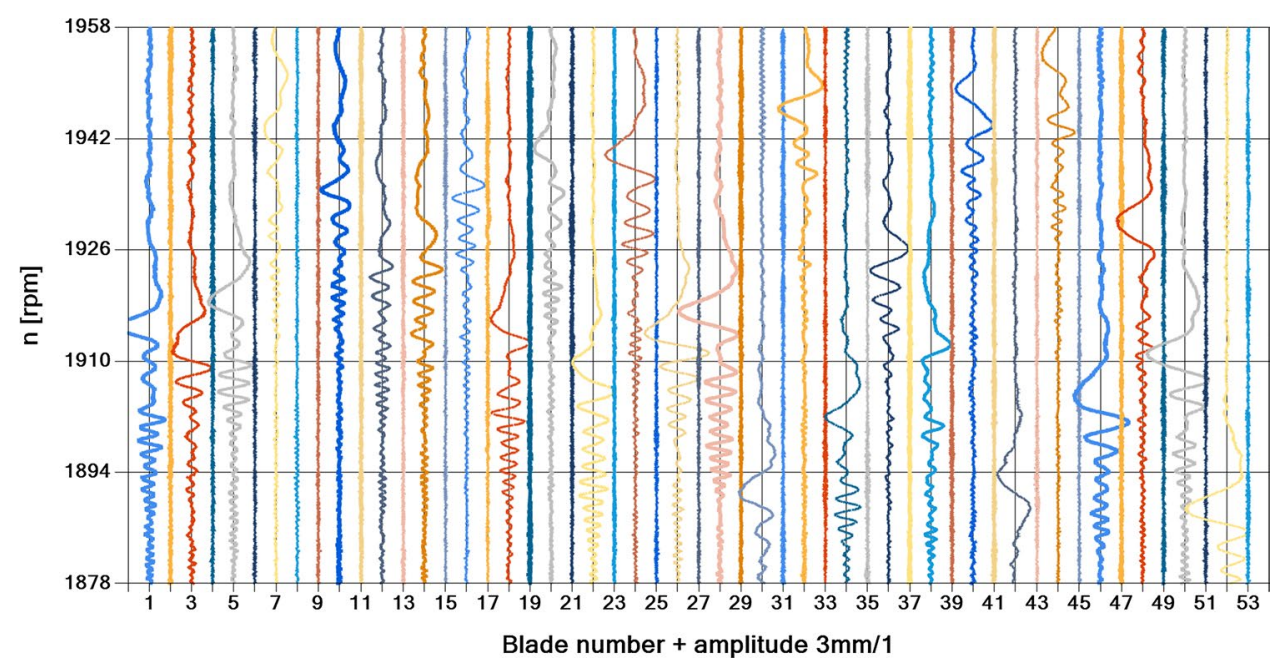

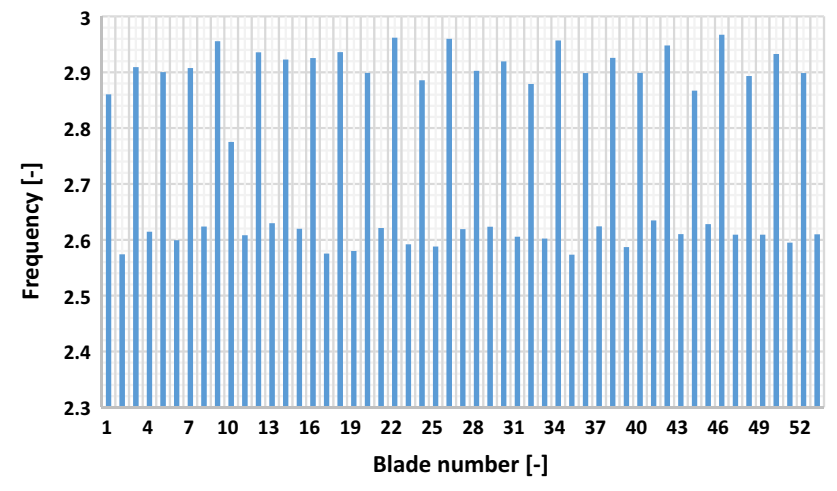

Fig. 4 Fifty-three rotor blade frequencies, based on rated speed, as the results of fathering

for 3EO. It shows the modes of the mistuned bladed disc. The maximum vibration amplitude of a given blade was selected and a line passing horizontally through all the other blades gave their vibration amplitudes at this level, providing the mode shape. This was repeated with all the other maximum vibration amplitudes. In such a way, the modes of mistuned bladed discs were determined for 3EO.

\section{Numerical Results}

To properly verify the experimental results, different models of bladed discs were assumed in [1]. The first one was simply a bladed disc without a shaft, and the second was a bladed disc with part of the shaft. The mode shapes of the mistuned bladed disc were different for each of the models. In this paper, a shaft with mistuned bladed discs will be considered (Fig. 5). The mistuned blade pattern was based on tip-timing measurements during the rated speed in a real turbine (Fig. 4).

A FEM model of bladed discs on the shaft of a last stage of a LP part of steam turbine was created (Fig. 5). 


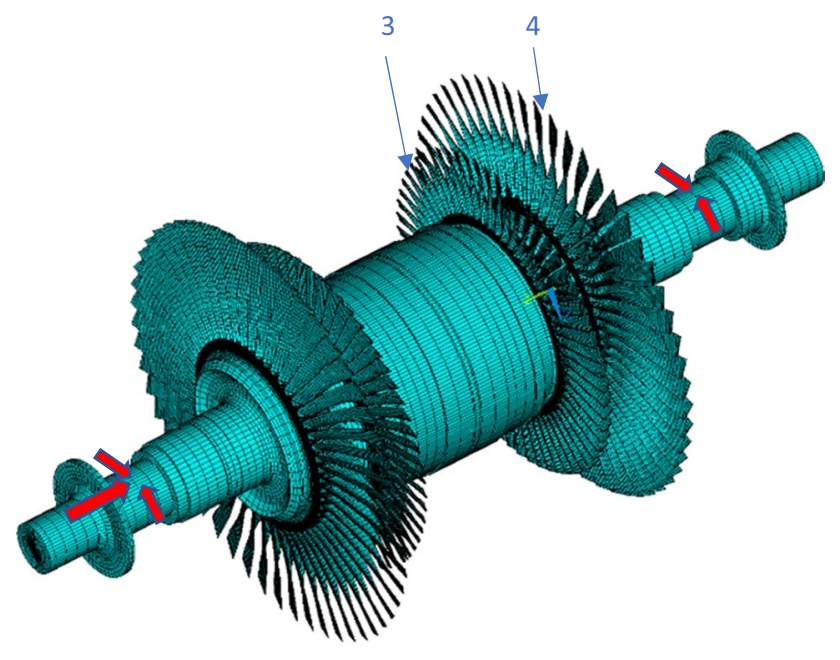

Fig. 5 LP stage rotor

The LP rotor consisted of two symmetrically arranged sets of four-bladed discs, numbered 1-4. Discs 1 and 2 with short shrouded blades were modelled using discs with no blades. An eight-node isoparametric brick element was used. A single blade had about 12,300 dofs, and the whole model had 6 million dofs. The free vibration analysis was done using the ANSYS code. Model was set up in the rotating frame of reference in ANSYS. The centrifugal effects as well as spin softening were included. The stiffness and damping of journal bearing were not included.
On one rotor end, deflections in three main directions were neglected; on second end, deflection in radial directions is neglected. A mistuning in blades was introduced via various Young modulus values according to feathering procedure.

To properly assume the response of the mistuned bladed disc, the transient forced vibration analysis [21] had to be carried out using single air pipe excitation. Such an analysis would require small speed windows, which will be done in future.

Mistuning 'destroys' cyclic symmetry properties-one can only identify the nodal diameter content by means of a Fourier analysis around the blade row circumference. Three groups of frequencies were assumed (Fig. 4): without feathering (2.93 to 2.89-non-dimensional frequency, 26 blades), with feathering (2.62-2.57, 26 blades) and blade 4 (2.77). There was less than $10 \mathrm{~Hz}$ mistuning difference between the group with feathering and the one without feathering. The tip-timing measurements show that in the first group (2.93-2.89, 26 blades) without feathering and also in the group with feathering (2.62-2.57, 26 blades) another mistuning appeared as the result of a manufacturing error (Fig. 4).

Figure 6 shows the first, fourth, fifth, seventh, eleventh and fourteenth modes corresponding to the first bladed disc frequency series of two geometrically and identically mistuned bladed disc number 4) on the shaft at $1850 \mathrm{rpm}$. Figure 7 shows the first, fourth, fifth, seventh, eleventh
Fig. 6 The first (a), fourth (b), fifth (c), seventh (d), eleventh (e), fourteenth (f) - modes first group for the mistuned laststage LP turbine bladed disc, mistuned bladed disc on shaft

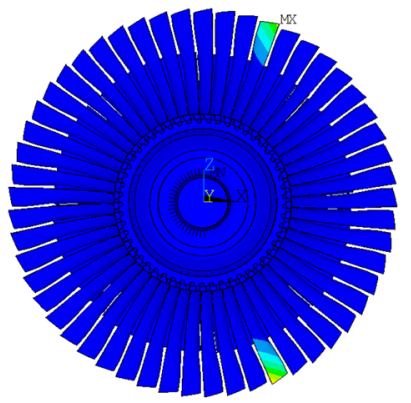

a

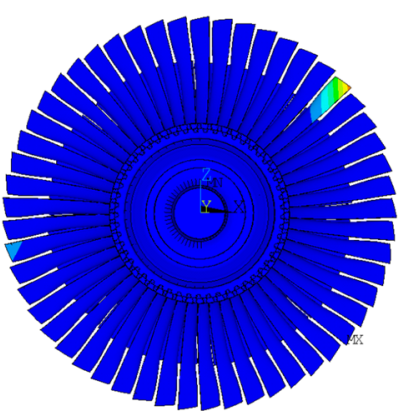

d

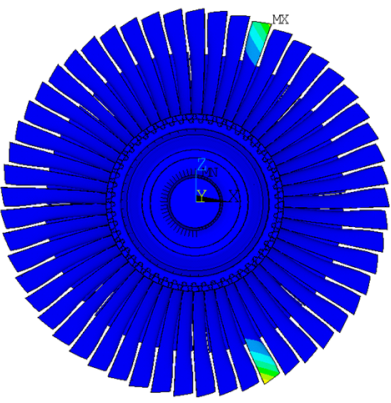

b

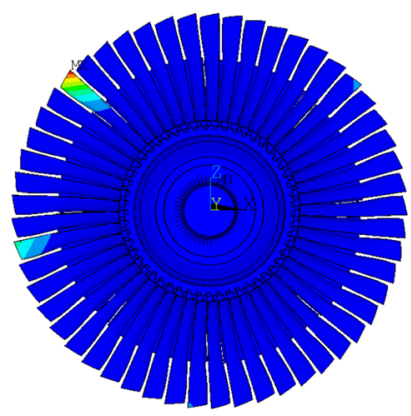

e

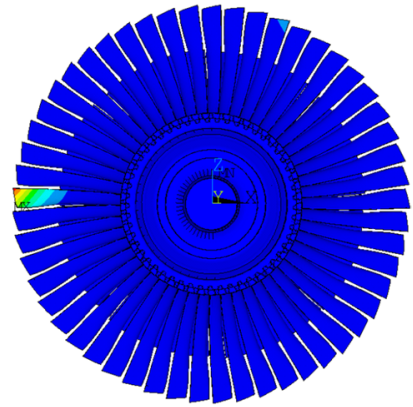

c

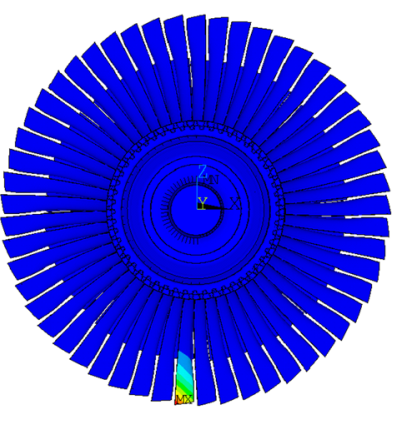

f 
Fig. 7 The first (a), fourth (b), fifth (c), seventh (d), eleventh (e), fourteenth (f) mode shapes-first group, for the mistuned last stage LP turbine bladed disc, single mistuned bladed disc

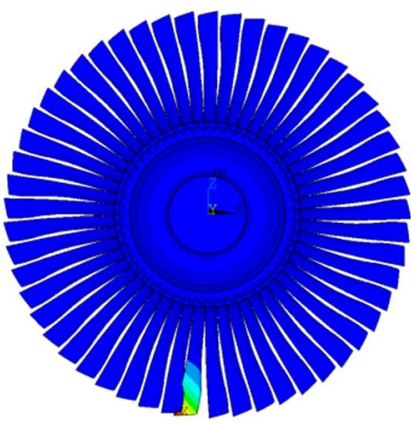

a

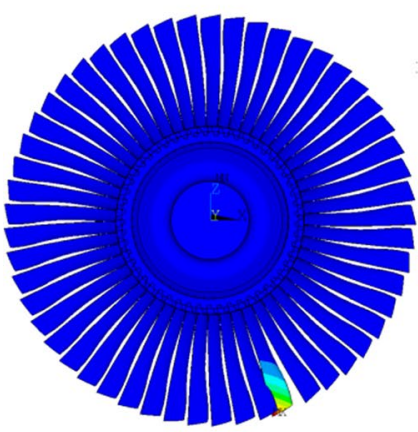

d

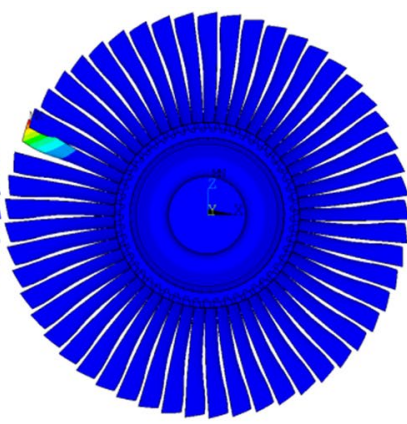

b

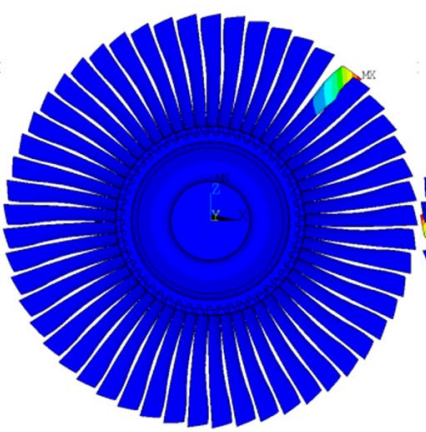

e

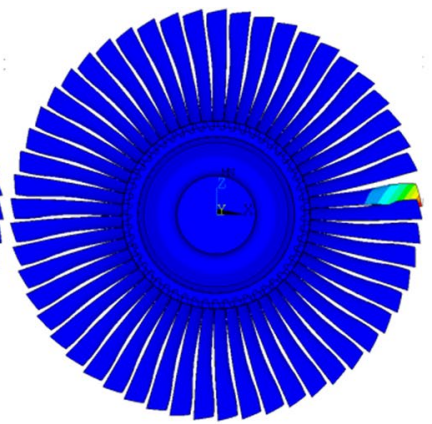

c

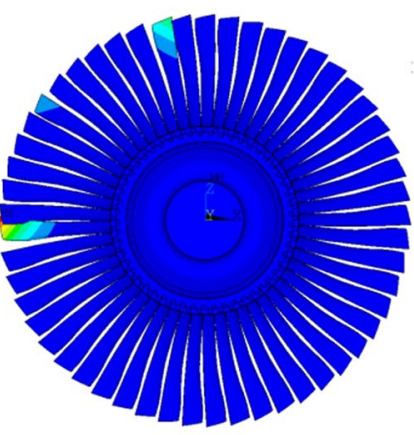

f and fourteenth modes corresponding to the first frequency series of mistuned single-bladed disc at $1850 \mathrm{rpm}$.

Figure 6 shows that the mode shapes of the mistuned bladed disc in the first series do not have a nodal diameter. The modes of the mistuned bladed discs without a shaft and with part of the shaft are slightly different from each other [1] and also different from the mistuned bladed disc on the shaft.

The above results show that modes of a single mistuned bladed disc are different than those of mistuned bladed discs on a shaft.

\section{Comparison of Numerical and Experimental Results}

The tip-timing measurements give the frequencies and amplitudes of the mistuned bladed disc modes on shaft. Figure 8 compares several experimentally measured (blue) and numerically calculated mistuned bladed disc modes on shaft (green) and single mistuned bladed disc (red). In some modes, the comparison is satisfactory only for mistuned bladed disc on shaft. Discrepancies result from many factors, including the way the mistuning was modelled, friction in the blade root area, multistage coupling, a rigid support of the full shaft in bearings instead of the stiffness and bearing damping coefficients. The results show that nodal diameters do not appear in the first mode family associated with the fundamental mode shape of a cantilevered blade and only individual blades vibrate.

The numerical mode shapes were scaled down to unity, and next they were scaled up to the maximal mode shape values from the experimental measurements.

\section{Conclusions}

This paper has shown the vibration modes of a LP mistuned last-stage bladed disc. For the first time, a shaft with four bladed discs was created to analyse multistage coupling and the influence of the whole shaft on mistuned bladed disc modes. The blade mistuning pattern was measured by tiptiming in a vacuum spin chamber. The experimental results from the tip-timing analysis show that nodal diameters do not appear in the first mode family associated with the natural frequencies of a cantilever blade and only individual blades vibrate. The numerical results confirm this. In general, mistuning destroys nodal diameters, but some blades vibrate in a pattern that can be characterized by the Fourier analysis. In this paper, a small mistuning of $0.5 \%$ influenced the mode in such a way that only a single blade vibrated. But this conclusion only applies to long (in this case $1 \mathrm{~m}$ ) blades.

Normally, in the calculation of flutter, the interblade phase angle can be assumed in advance [22]. Interblade phase angle is connected with nodal diameters. In the last 

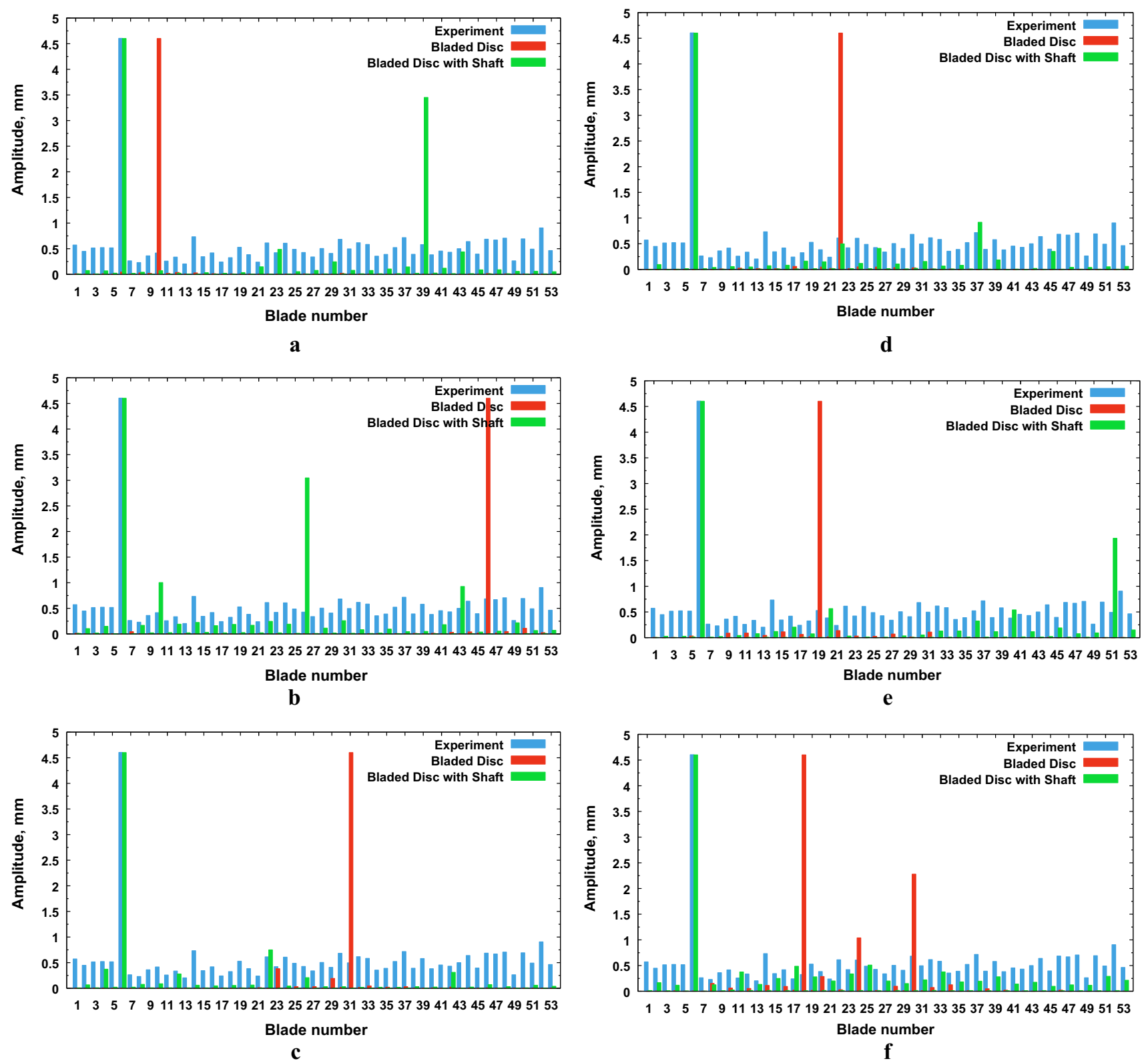

Fig. 8 Experimentally and numerically obtained mistuned bladed disc first (a), fourth (b), fifth (c), seventh (d), eleventh (e), fourteenth (f) modes

stage, however, modes with nodal diameters do not exist in the first series family. Therefore, flutter has to be calculated in each particular mode.

This research has been financed by Polish Ministry of Science (NCBiR) funds as development project POIR.04.01.0400-0116/17. All the numerical calculations were carried out at the Academic Computer Centre TASK (Gdansk, Poland).

Open Access This article is distributed under the terms of the Creative Commons Attribution 4.0 International License (http://creativeco mmons.org/licenses/by/4.0/), which permits unrestricted use, distribution, and reproduction in any medium, provided you give appropriate credit to the original author(s) and the source, provide a link to the Creative Commons license, and indicate if changes were made.

\section{References}

1. Kubitz L, Rzadkowski R (2018) LP last stage steam turbine blade vibrations due to mistuning. J Vib Eng Technol 3(3):309-316

2. Przysowa R, Spychała J, Majewski P, Rokicki E (2017) Experimental analysis of rotor blades in vacuum chamber. In: Rzadkowski R, Szczepanik R (eds) Dynamics of the last stage low pressure steam turbine rotor blades. ITWL, Warsaw 
3. Przysowa R, Spychała J, Majewski P, Rokicki E (2017) Monitoring of blade vibration in a steam turbine power station. In: Rzadkowski R, Szczepanik R (eds) Dynamics of the last stage low pressure steam turbine rotor blades. ITWL, Warsaw

4. Rzadkowski R, Rokicki E, Piechowski L, Szczepanik R (2016) Analysis of middle bearing failure in rotor jet engine using tiptiming and tip-clearance techniques. Mech Syst Signal Process 76-77:213-227

5. Szczepanik R, Rzadkowski R, Kwapisz L (2010) Crack initiation of rotor blades in the first stage of SO-3 compressor. Adv Vib Eng 9(4):357-362

6. Sanvito M, Pesatori E, Bachschmidt N, Chatterton S (2012) Analysis of LP steam turbine blade vibration: experimental results and numerical simulations, 189-197, 10th International Conference on Vibrations in Rotating Machinery, 11-13 Sept 2012, London, C1326/043, p. 189, IMechE

7. Mazur Z, Hernandes-Rosette A, Garcia-Illescseas R (2006) Investigation of the failure of L-O blades. Eng Fail Anal 13(8):1338-1350

8. Mcbean I, Masserey PA, Havakechian S (2010) The development of long last stage steam turbine blade, ASME Turbo Expo 2010, power for land, Sea and air (GT-2010), June 14-18, 2010, Glasgow UK, Paper 2010-22747, pp. 2245-2256

9. Hsiao-Wei DC, Chi-Chih C, Chih-Neng H, Gwo-Chung T, Kwang-Lu K (2003) An Investigation of turbomachinery shrouded rotor blade flutter, ASME Turbo Expo 2003, International Joint Power Generation Conference (GT-2003), June 16-13, 2003, Atlanta, Georgia, USA, Paper GT2003-38311, pp. 331-338

10. Kielb R, Barter J, Chernycheva O, Fransson T (2004) Flutter of the low pressure turbine blades with cyclic-symmetric modes: a preliminary design method. J Turbomach 126(3):306-309

11. Bladh R, Castanier M, Pierre C (2003) Effects of multistage coupling and disc flexibility on mistuned bladed disc dynamics. J Eng Gas Turbines Power 125:121-130

12. Shahab AAS, Thomas J (1987) Coupling effects of disc flexibility on the dynamics behaviour of multi disc-shaft system. J Sound Vib 114(3):435-452
13. Sharma BK, Devadig HV, Singh AK (2005) Modal time history analysis of a steam turbine rotor to an earthquake excitation-A 3D approach. Adv Vib Eng 4(4):351-359

14. Sinha A (2007) Reduced-order model of mistuned multi-stage bladed rotor, Proc. of ASME Turbo Expo 2007: power for land, sea and air, May 14-17, Montreal, Canada

15. Laxalde D, Lombard J-P, Thouverez F (2007) Dynamics of multistage bladed discs systems, Proc. Of ASME Turbo Expo 2007: power for land, sea and air, May 14-1, Montreal, Canada

16. Rządkowski R, Drewczyński M (2012) Coupling of vibration of several bladed multistage coupling of eight bladed discs on a solid shaft. Adv Vib Eng 11(3):301-316

17. Rządkowski R, Maurin A (2013) Multistage coupling of eight mistuned bladed discs on a solid shaft, part I. free vibration analysis. Adv Vib Eng 12(3):267-285

18. Rzadkowski R, Maurin A (2014) Multistage coupling of eight mistuned bladed discs on a solid shaft of the steam turbine, Forced Vibration Analysis. J Vib Eng Technol 2(6):495-508

19. Rzadkowski R, Maurin A (2014) Multistage coupling of eight mistuned bladed disks on a solid shaft of the steam turbine. J Vib Eng Technol 2(6):495-508

20. Rzadkowski R (2018) Dynamic multi-stage analysis of a mistuned aircraft rotor with foreign object ingestion. J Vib Eng Technol 6(5):339-355

21. Rzadkowski R (1996) Transient nozzle excitation of mistuned bladed discs. J Sound Vib 190(4):629-643

22. Rzadkowski R, Kubitz L, Gnesin V, Kolodyazhnaya L (2018) Flutter of long blades in a steam turbine. J Vib Eng Technol 3(3):289-296

Publisher's Note Springer Nature remains neutral with regard to jurisdictional claims in published maps and institutional affiliations. 